International Journal of Advanced Chemistry, 8 (1) (2020) 189-191
International Journal of Advanced Chemistry
SPC
Website: $w w w$. sciencepubco.com/index.php/IJAC
Research paper

\title{
Hydride generation atomic fluorescence spectrometry (HG-AFS) determination of total arsenic in lipstick
}

\author{
M. E. Ghanjaoui ${ }^{1,2 *}$, I. Adraoui ${ }^{3}$, A. Gammoun ${ }^{1}$, L. Cervera ${ }^{1}$, M. El Rhazi ${ }^{2}$, M. de la Guardia ${ }^{1}$ \\ ${ }^{1}$ Department of Analytical Chemistry, University of Valencia, 46100 Burjassot (Valencia) Spain \\ ${ }^{2}$ Laboratory of Electrochemistry and Chemical Physics, Faculty of Sciences and Technologies (Mohammedia) Morocco \\ ${ }^{3}$ Laboratory of Biotechnology, Materials and Environment, University Ibn Zohr, BP 8106, Cite Dakhla, Agadir, Morocco \\ *Corresponding author E-mail:ghanjaoui2000@hotmail.com
}

\begin{abstract}
This study aimed to determine the total arsenic concentration in lipsticks and evaluate the potential health risks due to daily ingestion of this toxic element from this product. The samples were analyzed using atomic fluorescence spectrometry technique after mineralization and hydride generation (HG-AFS). The calibration curve is linear over a concentration range from 0.125 to $2 \mu \mathrm{g} \mathrm{L}^{-1}$ with a regression coefficient of the order of 0.9899 . The limit of detection is reaches $3 \mathrm{ng} \mathrm{g}^{-1}$. The standard deviation is of the order of $4 \%$. The accuracy of this method was evaluated by calculating the recoveries of additions of arsenic to three lipstick samples. These results indicate recovery rates between $91 \%$ and $98 \%$. Finely, the results found demonstrate that the method used in this work is suitable for arsenic detection in lipsticks samples.
\end{abstract}

Keywords: Lipstick;Atomic Fluorescence Spectrometry; Mineralization; Hydride Generation;Risk Assessment.

\section{Introduction}

Trace elements are present in the environment and can enter the raw materials in trace amounts. Generally cosmetics like skin-care creams, lotions, powders, perfumes, lipsticks and many other types of products are made from mixtures of chemical compounds some are derived from natural sources or synthetic. Dermal exposure would be the main route of exposure for cosmetics since most cosmetics are applied to the skin causes low-grade of toxicity. Dermal absorption of trace elements is relatively low; the absorption of individual elements is influenced by a number of factors including the physicochemical properties of mixtures [1].

Some of the ingredients in cosmetics are toxic to our health. Most have been narrowly tested and allergic responses are very common with the use of cosmetic. Heavy metals like lead, arsenic and cadmium are relatively added to the cosmetics for colour, odour and to increase surface adhesion or for biological response [2].

Lipstick is one of the decorative cosmetic products containing $65 \%$ castor oil, $15 \%$ beeswax, $10 \%$ carnuba wax, $5 \%$ lanolin, dyes, pigments and fragrances [3], which are applied to the color and texture of the lips.

Currently there are no international standards for trace element levels in cosmetics. The German Federal Government has conducted studies to identify the levels of trace elements in cosmetic products. According to its studies, the trace element levels in cosmetics exceeding the following values are considered technically unusable (Lead: 20 ppm, Arsenic: 5 ppm, Cadmium: 5 ppm, Antimony: 10 ppm) [4].

Manufacturers are theoretically aware of these issues and their products are normally subject to various controls, particularly from an allergenic point of view. A study carried out as part of the "Campaign for safe cosmetics" [5] by an American consumer protection association as part of the "Campaign for safe cosmetics" [5] showed that in 2007, lead was still found in $61 \%$ of the 33 brands of lipsticks tested and sold in the United States; lead levels ranged from 0.03 to $0.65 \mathrm{ppm}$, doses that remain relatively low, but when applied to mucous membranes, they are likely to be in contact with food and can be toxic. In one third of the cases, these lipsticks contained more lead than the amount allowed by the US Food and Drug Administration in candy $(0.1 \mathrm{ppm})$ [5]. However, even in a country like the USA, there is a lack of standards for trace elements in this type of cosmetics. The study conducted by the American association therefore showed that the most expensive lipsticks were often those that contained the most lead [6].

In 2007, the U.S. Food and Drug Administration suggested that the comparison between the lead exposure pathway in the two cases (lipstick and candy) is not a fair comparison because candy is intended to be ingested over a regular period of time while lipstick is a product intended for topical use, and is ingested in much smaller amounts than candy [7].

Atomic fluorescence spectrometry (AFS) is an analytical technique that has been widely used for the determination of arsenic and other volatile elements [8] -[11]. The coupling of hydride generation (HG) and AFS allows determinations with low quantification limit, its instrumentation being cheaper than other conventional analytical techniques [12]. 
In this work, we will focus more specifically on the development of gentle digestion method for the detection of trace elements in lipstick. The technique that will be used is atomic fluorescence spectrometry after mineralization and hydride generation (HG-AFS).

\section{Materials and methods}

\subsection{Procedure for arsenic analysis by HG-AFS}

The PS Analytical Millennium Excalibur atomic fluorescence spectrometer (Kent, UK) was used for the detection of arsenic. The system is equipped with an arsenic hollow cathode lamp (discharge lamps) (Official Distributor PHOTRON, Victoria, Australia).

A sand bath PL 5125 Scharlau Raypa (Barcelona, Spain) and a Eurotherm muffle furnace K1253 equipped with a temperature control program 902 Heraeus (Madrid, Spain) were used to perform the mineralization of our samples.

\subsection{Reagents and solutions}

All solutions were prepared using high-purity water. The stock standard solutions $\left(1.000 \mathrm{mg} \mathrm{mL}^{-1}\right)$ of As (III) were obtained by dissolving appropriate amounts of $1.320 \mathrm{~g}$ of arsenic oxide $\mathrm{As}_{2} \mathrm{O}_{3}$ obtained from Riedel-de Haen (Hanover, Germany) in $25 \mathrm{ml}$ of $20 \%$ (w/v) potassium hydroxide $\mathrm{KOH}$, neutralization and dilution of the resulting solution was performed with $20 \%$ (v/v) $\mathrm{H}_{2} \mathrm{SO}_{4} \mathrm{Sulfuric}$ acid up to 11 .

For HG-AFS analysis, a 50\% (w/v) potassium iodide reducing solution prepared from potassium iodide KI (Merck) and a 10\% (w/v) solution of ascorbic acid obtained from charlau were used to reduce As(V) to As(III).

A $0.7 \%$ w/v solution of sodium tetrahydroborate $\mathrm{NaBH}_{4}$ (Fluka) was prepared in $0.1 \mathrm{~mol} \mathrm{~L}^{-1}$ of sodium hydroxide $\mathrm{NaOH}$ to generate the arsenic hydrides easily decomposable when analyzed by AFS atomic fluorescence spectrometry. This solution must be prepared and filtered daily before use.

The standard solutions have been prepared from 0.125 to $2 \mathrm{~g} \mathrm{~L}^{-1}$ in $30 \mathrm{~mL}$ plastic vials with the addition of $600 \mathrm{~L}$ of potassium iodide $\mathrm{KI}$ reducing solution $(50 \%)$ to each vial.

\subsection{Preparation and the determination of arsenic by HG AFS}

The high-temperature calcination of $0.5 \pm 0.005 \mathrm{~g}$ of the lipstick samples was carried out with the addition of $2.5 \mathrm{~mL}$ of a stabilizing solution of $20 \%(\mathrm{w} / \mathrm{v}) \mathrm{Mg}\left(\mathrm{NO}_{3}\right)_{2}-6 \mathrm{H}_{2} \mathrm{O}$ and $2 \%(\mathrm{w} / \mathrm{v}) \mathrm{MgO}$ which inhibits the formation of metal hydrides during mineralization and 5 $\mathrm{mL}$ of $50 \%(\mathrm{v} / \mathrm{v})$ nitric acid. The mixture is first evaporated in a sand bath and then mineralized in a muffle furnace at $450{ }^{\circ} \mathrm{C}$, with a gradual increase in temperature [1]. The resulting white ash was treated with $1 \mathrm{~mL}$ of ultrapure water and $9 \mathrm{~mL}$ of $10 \%$ (v/v) hydrochloric acid. A volume of $3 \mathrm{~mL}$ of each of the resulting solutions was transferred to $50 \mathrm{~mL}$ plastic vials. $8.75 \mathrm{~mL}$ of $37 \%$ (v/v) concentrated hydrochloric acid $\mathrm{HCl}$ and 6001 of a $50 \%(\mathrm{w} / \mathrm{v})$ reducing solution of $\mathrm{KI}$ and $10 \%$ ascorbic acid have been added. The solutions were adjusted with ultrapure water to $30 \mathrm{ml}$. Total arsenic was analysed by atomic fluorescence spectrometry according to the experimental conditions shown in Table 1.

Table 1: Operating Conditions of the HG-AFS Instrument for the Determination of Arsenic

\begin{tabular}{|c|c|}
\hline Parameter & Setting \\
\hline Arsenic Wave length (nm) & 197,3 \\
\hline $\mathrm{NaBH}_{4}$ concentration $(\%)(\mathrm{w} / \mathrm{v})$ & 0,7 \\
\hline Flow rate of Argon $\left(\mathrm{mL} \mathrm{min}^{-1}\right)$ & 330 \\
\hline Flow rate of Air $\left(\mathrm{L} \mathrm{min}^{-1}\right)$ & 2,5 \\
\hline Sample flow rate $\left(\mathrm{mLmin}^{-1}\right)$ & 9 \\
\hline $\mathrm{NaBH}_{4}$ flow rate $\left(\mathrm{mLmin}^{-1}\right)$ & 4,5 \\
\hline
\end{tabular}

\section{Results and discussions}

\subsection{Arsenic calibration curve}

The arsenic calibration curve was performed using atomic fluorescence spectrometry after mineralization and hydride generation using the conditions shown in Table 2.

The calibration curve is linear over a concentration range from 0.125 to $2 \mu \mathrm{g} \mathrm{L} \mathrm{L}^{-1}$ with a regression coefficient of the order of 0.9899 . The limit of detection is calculated over five blank repeats in the lipstick samples analyzed, it reaches $3 \mathrm{ng} \mathrm{g}^{-1}$. The standard deviation calculated on five different samples is of the order of $4 \%$ (Table 2).

Table 2: Regression Line Characteristics

\begin{tabular}{ll}
\hline Parameter & Valeur \\
\hline As concentration range $\left(\mu \mathrm{g} . \mathrm{L}^{-1}\right)$ & $0.125-2$ \\
Regression equation & $\mathrm{Y}=11+123 * \mathrm{C}$ \\
Regression coefficient $\left(\mathrm{r}^{2}\right)$ & 0,9899 \\
Standard deviation $(\mathrm{RSD}) \mathrm{n}=5$ & $4 \%$ \\
The limit of detection $\left(\mathrm{ng} \mathrm{g}^{-1}\right)$ & 3 \\
\hline
\end{tabular}

\subsection{Analysis of total arsenic in lipstick by HG-AFS}

The high-temperature calcinations procedure described in was combined with atomic fluorescence spectrometry and hydride generation to evaluate the arsenic content of lipstick samples. In Table 3 we have presented the results obtained in four samples of lipstick purchased from the local valence market, the concentration range obtained for arsenic is between 30 and $250 \mathrm{ng} \mathrm{g}^{-1}$. The concentration values obtained in all samples are well below the limit recommended by the German federal government (5ppm). 
The accuracy of this method was evaluated by calculating the recoveries of tree additions $\left(100,200\right.$ and $\left.300 \mathrm{ng} \mathrm{g}^{-1}\right)$ to the four lipstick samples. These results indicate that the recovery rates between $91 \%$ and $98 \%$.

Table 3:Results of the Analysis of Arsenic Levels in Ng G-1 in Four Lipstick Samples Using HG-AFS

\begin{tabular}{|c|c|c|c|c|}
\hline $\mathrm{N}^{\circ}$ & Color & Added & As Found ng g-1 & Recovery (\%) \\
\hline 1 & Red & - & $250 \pm 11$ & - \\
\hline 2 & Pink & - & $30 \pm 2$ & - \\
\hline 3 & Dark red & - & $90 \pm 3$ & - \\
\hline 4 & Shemmering beige & - & $61 \pm 2$ & - \\
\hline 1 & Red & $100 \mathrm{ng} \mathrm{g}-1$ & $342 \pm 13$ & 98 \\
\hline 2 & Pink & $100 \mathrm{ng}$ g-1 & $121 \pm 5$ & 93 \\
\hline 3 & Dark red & 100 ng g-1 & $179 \pm 6$ & 94 \\
\hline 4 & Shemmering beige & $100 \mathrm{ng}$ g- 1 & $154 \pm 7$ & 96 \\
\hline 2 & Pink & $200 \mathrm{ng}$ g- 1 & $215 \pm 9$ & 93 \\
\hline 3 & Dark red & $200 \mathrm{ng}$ g-1 & $265 \pm 14$ & 91 \\
\hline 4 & Shemmering beige & 200 ng g-1 & $255 \pm 12$ & 98 \\
\hline 1 & Red & $300 \mathrm{ng}$ g-1 & $520 \pm 28$ & 95 \\
\hline 2 & Pink & 300 ng g-1 & $308 \pm 16$ & 93 \\
\hline 3 & Dark red & $300 \mathrm{ng}$ g-1 & $358 \pm 15$ & 92 \\
\hline 4 & Shemmering beige & $300 \mathrm{ng}$ g-1 & $343 \pm 11$ & 95 \\
\hline
\end{tabular}

\section{Conclusion}

The proposed method has suitable for the determination of arsenic in lipstick samples. The arsenic contents found in the all the lipsticks samples analyzed are lower than the maximum limited permissible contamination. These results show that the samples analyzed do not present a real danger.

\section{References}

[1] E.L. Sainio, R. Jolanski, E. Hakala, L. Kanerva, Contact Dermatitis 42, 5 (2000).https://doi.org/10.1034/j.1600-0536.2000.042001005.x.

[2] Barczac C. Hazards of cosmetics. (Place unknown): AEHA Quarterly summer;Environmental health association of Novascotia; 1995. (updated June 22 1995; cited 2014 Oct.).

[3] A.M.L. Barker and P.D.B. Journal of the Forensic Science Society, 12 (1972) 449.https://doi.org/10.1016/S0015-7368(72)70712-4.

[4] Bundesgesundheitsblatt (revue fédérale sur la santé, Allemagne), 28 (1985) Nr. 7, 216.

[5] US FDA, Lead in Candy Likely to Be Consumed Frequently by Small Children: Recommended Maximum Level and Enforcement Policy, 2006a.

[6] The Campaign for Safe Cosmetics, A Poison Kiss, The Problem of Lead in Lipstick, October 2007.

[7] US FDA, Lipstick and Lead, 2007a.

[8] Ferreira HS, Matos-Reyes MN, Cervera ML, Ferreira SLC, de la Guardia M (2011) Screening of toxic inorganic arsenic species in garlic (Allium sativum L.). Food Anal Method 4:447https://doi.org/10.1007/s12161-010-9187-8.

[9] Ferreira SLC, Silva LOB, de Santana FA, Junior MMS, Matos GD, dos Santos WNL (2012) A review of reflux systems using cold finger for sample preparation in the determination of volatile elements. Microchem J.https://doi.org/10.1016/j.microc.2012.08.015.

[10] Fu Y, Chen M, Bi X, He Y, Ren L, XiangW, Qiao S, Yan S, Li Z, Ma Z (2011) Occurrence of arsenic in brown rice and its relationship to soil properties from Hainan Island, China. Environ Pollut 59:1757https://doi.org/10.1016/j.envpol.2011.04.018.

[11] Walter N. L. dos Santos and all; "Slurry Sampling and HG AFS for the Determination of Total Arsenic in Rice Samples"; Food Anal. Methods (2013) 6:1128-1132https://doi.org/10.1007/s12161-012-9519-y.

[12] Rehna Saidalavi and all (2017), Analysis of lead and arsenic in cosmetics and assessment of students awareness about cosmetic toxicity, International Journal of Basic \& Clinical Pharmacology Vol 6, Issue 6.https://doi.org/10.18203/2319-2003.ijbcp20172235. 